\title{
Effects of different metastasis patterns, surgery and other factors on the prognosis of patients with stage IV non-small cell lung cancer: A Surveillance, Epidemiology, and End Results (SEER) linked database analysis
}

\author{
YI LIAO, XIANMING FAN and XUE WANG \\ Department of Respiratory Medicine, The Affiliated Hospital of Southwest Medical University, \\ Luzhou, Sichuan 646000, P.R. China
}

Received October 3, 2018; Accepted April 10, 2019

DOI: $10.3892 / \mathrm{ol} .2019 .10373$

\begin{abstract}
The surgical treatment of patients with advanced lung cancer remains controversial. The current study aimed to identify the factors affecting the prognosis of patients with stage IV non-small cell lung cancer (NSCLC) and to clarify the surgery guidelines. A total of 27,725 patients diagnosed with stage IV NSCLC were selected from the Surveillance, Epidemiology, and End Results program between 2010 and 2013. The sex, age, ethnicity, marital status, Tumor-Node-Metastasis stage, radiation therapy received and surgical status of each patient were recorded. Patients were followed up to November 2015. Survival rates were estimated by the Kaplan-Meier method. Single- and multi-factor analyses were performed using the log-rank test and multivariate Cox regression analysis respectively. In the isolated organ metastasis cohort, patients with liver metastasis alone had the worst prognosis, with a median overall survival (OS) of 4 months (liver metastasis vs. other organ metastases; $\mathrm{P}<0.001)$. Patients with lung metastasis only had the best prognosis, with a median OS of 8 months (lung metastasis vs. other organ metastases; $\mathrm{P}<0.001)$. Furthermore, patients with only one metastasis had the best prognosis, with a median OS of 6 months (single metastasis vs. multiple-organ metastases; $\mathrm{P}<0.001$ ). The multivariate Cox regression analysis of the isolated-organ metastasis cohort and the multiple-organ metastases cohort revealed that patients who were $\leq 60$ years, female, married, Asian, with $\mathrm{N}_{0}$ stage, had only bone metastasis, accepted wedge resection or lobectomy of the primary tumor, had surgical procedure to distant lymph node(s), and
\end{abstract}

Correspondence to: Dr Xianming Fan or Dr Xue Wang, Department of Respiratory Medicine, The Affiliated Hospital of Southwest Medical University, 25 Taiping Street, Luzhou, Sichuan 646000, P.R. China

E-mail: fxm129120@sina.com

E-mail:wx15883059402@163.com

Key words: non-small cell lung cancer, prognosis, surgery, prognosis, Surveillance, Epidemiology, and End Results program received beam radiation had an improved prognosis compared with the other patients. Age, sex, tumor type, ethnicity, N stage, number and type of metastatic lesions, surgical treatment of primary and metastatic lesions and radiation therapy are factors which influence the prognosis of patients with stage IV NSCLC. Furthermore, surgery may still benefit these patients.

\section{Introduction}

Lung cancer is among the most common malignant tumors and has increasing rates of morbidity and mortality worldwide (1). It is estimated that $\sim 234,000$ new lung cancer cases were diagnosed in 2018 in the United States, and that $\sim 154,000$ people will succumb to lung cancer in this year (2). The majority of patients with lung cancer $(85 \%)$ are diagnosed with non-small cell lung cancer (NSCLC), and $>80 \%$ of these patients have different degrees of metastasis (3).

The most common sites for lung cancer metastasis are the nervous system, bone, liver, respiratory system and adrenal glands. Bone metastasis is the most common in patients with lung adenocarcinoma (39\%) (4). The prognosis and survival rate of patients with advanced lung cancer are very poor, and the survival rate is not satisfactory. The median survival time of patients with stage IV NSCLC is 5 months (5). Patients with stage IV NSCLC with liver metastasis have the worst prognosis, $<3$ months (5).

With advances in cancer treatment, molecular targeted therapy and immunotherapy may provide alternatives to the conventional surgery, radiotherapy and chemotherapy. However, targeted therapy is not effective in people without epidermal growth factor receptor (EGFR) mutations (6). The emergence of drug resistance in tumor cells may lead to treatment failure in a patient population that is suitable for targeted therapy (7). In addition, both targeted therapy and immunotherapy may be economically unfeasible for patients with lung cancer $(8,9)$. Accordingly, cost-effective treatment alternatives for patients with lung cancer are required.

The gold standard treatment for patients with NSCLC with distant metastasis is a multidisciplinary comprehensive treatment including chemoradiotherapy, immunotherapy, targeted therapy and immunotherapy rather than surgery. 
Furák et al (10) reported that the 5-year survival rate of patients with NSCLC that did not undergo surgical treatment was $5.8 \%$. However, improvements in surgical techniques have improved the 5-year survival rate and median survival of patients with stage IV NSCLC (11-13). Therefore, surgical treatment in patients with stage IV NSCLC may be beneficial.

To date, there have been few large clinical retrospective studies on the surgical treatment of patients with stage IV NSCLC (11,12). Accordingly, the current study aimed to investigate whether surgical treatment may improve the outcome of patients with stage IV NSCLC, as well as to identify the factors which influence the prognosis of patients. Relevant cases were selected from the Surveillance, Epidemiology, and End Results (SEER) (https://seer.cancer.gov/) program for further analysis.

\section{Materials and methods}

Data collection. A total of 27,725 patients with stage IV NSCLC in the United States diagnosed between January 1, 2010 and December 31, 2013 with distinct metastatic sites in bone, brain, lung and liver and multiple metastases, that had received chemotherapy at least once, were selected from the SEER program. Patients included in this study were followed up between January 1, 2010 and November 31, 2016. Patients with incomplete or missing information were excluded. The distant metastatic lesions included only bone, brain, lung and liver. Other common sites, such as the pleura, adrenal gland and gastrointestinal tract were not included. The inclusion codes and criteria from the SEER database were are as follows: The primary tumor type was coded as lung (063), the coding of tumor pathological tissue classification was squamous cell neoplasms (02), and adenomas and adenocarcinomas (05). The following patient data were collected: i) Marital status; ii) ethnicity; iii) sex; iv) age at diagnosis; v) survival time (months); vi) overall survival (OS) and cancer-specific survival (CSS); vii) $\mathrm{T}$ stage; viii) $\mathrm{N}$ stage; ix) surgery of the primary site; $\mathrm{x}$ ) surgery of the metastatic sites; $\mathrm{xi}$ ) radiation therapy received; and xii) whether there was bone (not including the bone marrow), brain (not including the spinal cord or other parts of the central nervous system), lung (not including the pleura or pleural fluid) or liver metastasis. According to the SEER program definition, survival time means the time between diagnosis and death or the last follow-up time. OS is the time from the date of diagnosis to the death of any cause. CSS is the time from the date of diagnosis to the date of cancer-associated mortality. Surgery of the primary site describes a surgical procedure that removes and/or destroys tissue of the primary site performed as part of the therapy. Surgery of the metastatic sites describes the surgical removal of distant lymph node(s) or other tissue(s) or organ(s) beyond the primary site. According to the definition of the 7th Edition of the American Joint Committee on Cancer (AJCC) staging system (14), all the included patients with NSCLC were stage IV patients $\left(\mathrm{T}_{0-4} \mathrm{~N}_{0-3} \mathrm{M}_{1}\right)$, and the histopathological types included adenocarcinoma and squamous cell carcinoma. Patients with adenomas did not meet the above criteria and therefore were excluded from this study.

Statistical analysis. The $\chi^{2}$ test was used to compare the clinicopathological features of the patients included in the study and determine whether there were differences between different metastatic lesions. The Kaplan-Meier method was used to estimate the survival function, and the differences were evaluated with the log-rank test by pair comparison. Multivariate Cox regression analysis was conducted to assess the association of specific factors that impact overall survival (OS) and CSS. Additionally, the $95 \%$ confidence interval (CI) for all hazard ratio (HRs) estimates across all strata were calculated. $\mathrm{P}<0.05$ was considered to indicate a statistically significant difference. All statistical operations were performed using SPSS software (version 22.0; IBM Corp., Armonk, NY, USA).

\section{Results}

Patient characteristics. A total of 27,725 patients with NSCLC in the United States diagnosed from January 1, 2010 to December 31, 2013 were included in the current study. A total of 17,603 patients had one metastatic lesion while 10,122 patients had $\geq 2$ metastatic lesions. The number of patients with only bone, brain, lung and liver metastases was $5,989,4,255,5,717$ and 1,642, respectively. The number of patients with two, three and four metastatic lesions was 7,275, 2,389 and 458 respectively. The mean age of the patients was 67.51 years, with a median of 68 years (range, 13-102 years). A total of 737, 1,761 and 146 patients received surgical intervention for their primary lesion only, metastatic lesion only and both primary and secondary lesions, respectively. However, the specific surgical intervention for each patient was not recorded. The basic information of the patients is presented in Table I.

Survival outcomes. Survival analysis was performed to determine the OS of patients with the different isolated metastatic lesions. The median OS of patients with NSCLC with bone, brain, liver and lung metastases was 5, 6, 4 and 8 months, respectively. Patients with lung metastasis had an increased prognosis compared with the other patients $(\mathrm{P}<0.001$; Fig. 1$)$, while patients with liver metastasis had a decreased prognosis $(\mathrm{P}<0.001$; Fig. 1). Significant differences of median OS time between patients with different organ metastasis were indicated.

In addition, the OS was also assessed based on the number of metastatic lesions. The median OS of patients with NSCLC with one, two, three or four metastatic sites was 6, 4, 3 and 3 months, respectively. Patients with one metastatic lesion had a significant increased prognosis compared with patients with $>1$ metastatic lesion (Fig. 2). Patients with two metastases had a significantly improved prognosis compared with patients with three and four metastases (two sites vs. three sites, $\mathrm{P}<0.001$; two sites vs. four sites, $\mathrm{P}<0.001$; Fig. 2). However, there was no statistically significant difference in OS between patients with three and four metastatic lesions ( $\mathrm{P}=0.721$; Fig. 2).

The patients with only bone, brain, liver, lung metastasis and patients with multiple metastases were divided into groups according to whether the primary or metastatic lesions were treated by surgery, and their OS was subsequently estimated. Patients with bone, brain, liver, lung metastasis and multiple metastatic lesions had a significantly increased prognosis following surgery on the primary lesions compared with 
Table I. Clinicopathological characteristics of patients with metastatic non-small cell lung cancer.

\begin{tabular}{|c|c|c|c|c|c|c|c|}
\hline Variable & Bone metastasis & $\begin{array}{c}\text { Brain } \\
\text { metastasis }\end{array}$ & $\begin{array}{c}\text { Liver } \\
\text { metastasis }\end{array}$ & $\begin{array}{l}\text { Lung } \\
\text { metastasis }\end{array}$ & $\begin{array}{l}\text { Multiple } \\
\text { metastasis }\end{array}$ & $\chi^{2}$ value & P-value \\
\hline \multicolumn{8}{|l|}{ Age at diagnosis } \\
\hline$\leq 60$ & 1,483 & 1,493 & 335 & 1,101 & 3,087 & \multirow[t]{2}{*}{$5,842.255$} & \multirow[t]{2}{*}{$<0.001$} \\
\hline$>60$ & 4,506 & 2,762 & 1,307 & 4,616 & 7,035 & & \\
\hline \multicolumn{8}{|l|}{ Sex } \\
\hline Female & 2,417 & 2,021 & 692 & 2,684 & 4,517 & \multirow[t]{2}{*}{$3,38.394$} & \multirow[t]{2}{*}{$<0.001$} \\
\hline Male & 3,572 & 2,234 & 950 & 3,033 & 5,605 & & \\
\hline \multicolumn{8}{|l|}{ Tumor type } \\
\hline $\begin{array}{l}\text { Squamous cell } \\
\text { carcinomas }\end{array}$ & 1,569 & 838 & 603 & 1,958 & 1,934 & \multirow[t]{2}{*}{$6,989.873$} & \multirow[t]{2}{*}{$<0.001$} \\
\hline Adenocarcinoma & 4,420 & 3,417 & 1,039 & 3,759 & 8,188 & & \\
\hline \multicolumn{8}{|l|}{ Marital status } \\
\hline Unmarried & 2,643 & 2,042 & 783 & 2,820 & 4,462 & \multirow[t]{2}{*}{178.562} & \multirow[t]{2}{*}{$<0.001$} \\
\hline Married & 3,346 & 2,231 & 859 & 2,897 & 5,660 & & \\
\hline \multicolumn{8}{|l|}{ Ethnicity } \\
\hline Caucasian & 4,879 & 3,391 & 1,338 & 4,513 & 7,860 & \multirow[t]{4}{*}{$44,453.648$} & \multirow[t]{4}{*}{$<0.001$} \\
\hline African-American & 716 & 573 & 214 & 759 & 1,284 & & \\
\hline Asian & 387 & 282 & 83 & 432 & 948 & & \\
\hline Australoid & 7 & 9 & 7 & 13 & 30 & & \\
\hline \multicolumn{8}{|l|}{ T stage } \\
\hline 0 & 72 & 66 & 28 & 9 & 50 & \multirow[t]{5}{*}{$11,588.136$} & \multirow[t]{5}{*}{$<0.001$} \\
\hline 1 & 1,068 & 780 & 245 & 241 & 782 & & \\
\hline 2 & 1,871 & 1,452 & 490 & 665 & 1,808 & & \\
\hline 3 & 1,441 & 996 & 420 & 1,687 & 2,962 & & \\
\hline 4 & 1,537 & 991 & 459 & 3,115 & 4,520 & & \\
\hline \multicolumn{8}{|l|}{$\mathrm{N}$ stage } \\
\hline 0 & 1,637 & 1,253 & 475 & 1,646 & 1,827 & \multirow[t]{4}{*}{$8,358.724$} & \multirow[t]{4}{*}{$<0.001$} \\
\hline 1 & 616 & 424 & 145 & 349 & 764 & & \\
\hline 2 & 2,755 & 1,931 & 778 & 2,351 & 5,036 & & \\
\hline 3 & 984 & 647 & 244 & 1,371 & 2,495 & & \\
\hline \multicolumn{8}{|c|}{ Surgery of the primary site } \\
\hline No & 5,847 & 4,006 & 1,596 & 5,403 & 9,990 & $76,277.022$ & $<0.001$ \\
\hline Wedge resection & 75 & 84 & 27 & 200 & 105 & & \\
\hline Lobectomy & 59 & 156 & 18 & 102 & 24 & & \\
\hline Pneumonectomy & 8 & 9 & 1 & 12 & 3 & & \\
\hline Surgery of the metastase & & & & & & & \\
\hline No & 5,695 & 3,385 & 1,612 & 5,610 & 9,516 & $92,989.834$ & $\mathrm{P}<0.001$ \\
\hline $\begin{array}{l}\text { Surgical procedure to } \\
\text { other regional sites }\end{array}$ & 25 & 16 & 6 & 27 & 26 & & \\
\hline $\begin{array}{l}\text { Surgical procedure to } \\
\text { distant lymph node(s) }\end{array}$ & 24 & 26 & 3 & 20 & 51 & & \\
\hline $\begin{array}{l}\text { Surgical procedure to } \\
\text { distant site }\end{array}$ & 241 & 827 & 21 & 56 & 519 & & \\
\hline $\begin{array}{l}\text { Combination of all } \\
\text { the above }\end{array}$ & 4 & 1 & 0 & 4 & 10 & & \\
\hline Radiation therapy & & & & & & & \\
\hline No & 2,755 & 775 & 1,351 & 4,346 & 4,303 & $41,417.869$ & $\mathrm{P}<0.001$ \\
\hline Beam radiation & 3,226 & 3,476 & 289 & 1,362 & 5,801 & & \\
\hline Radioactive implants & 3 & 3 & 0 & 4 & 3 & & \\
\hline Radioisotopes & 2 & 0 & 1 & 1 & 6 & & \\
\hline $\begin{array}{l}\text { Combination of } 2 \text { or } \\
3 \text { above }\end{array}$ & 3 & 1 & 1 & 4 & 9 & & \\
\hline
\end{tabular}




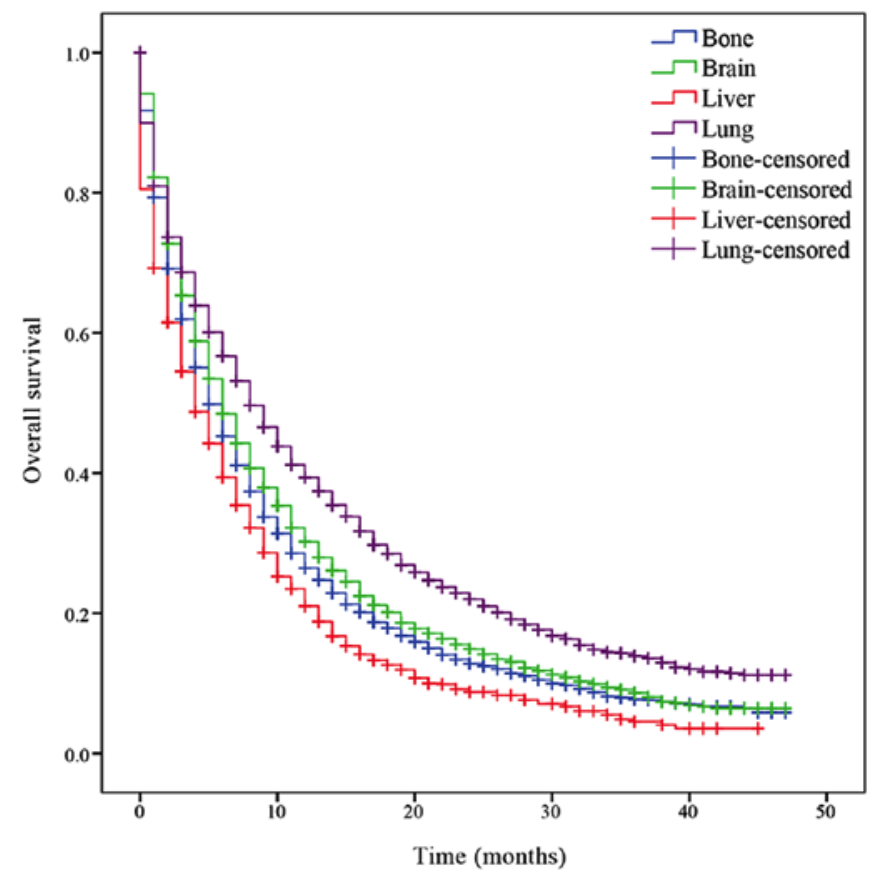

Figure 1. Kaplan-Meier curve of overall survival based on the site of isolated organ metastases. $\mathrm{P}<0.001$ bone metastasis vs. brain metastasis; bone metastasis vs. lung metastasis; bone metastasis vs. liver metastasis; brain metastasis vs. lung metastasis; brain metastasis vs. liver metastasis and lung metastasis vs. liver metastasis.

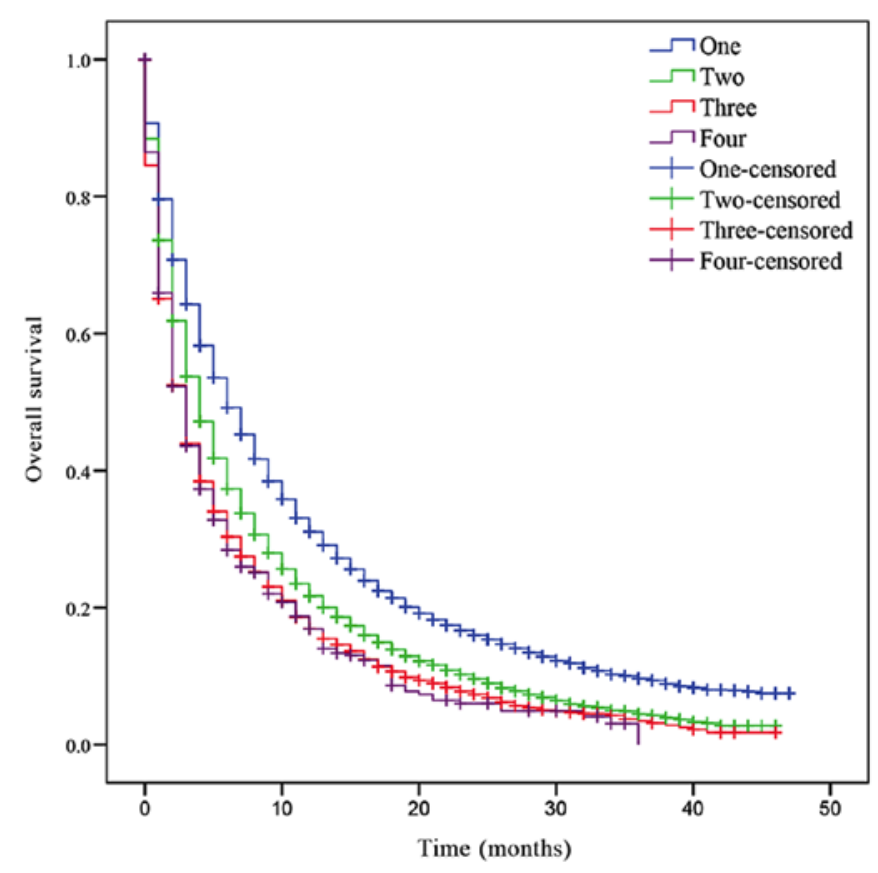

Figure 2. Kaplan-Meier curve of overall survival based on the number of metastatic organs. $\mathrm{P}<0.001$ one site vs. two sites; one site vs. three sites; one site vs. four sites; two sites vs. three sites and two sites vs. four sites. $\mathrm{P}=0.721$ three sites vs. four sites.

patients who had not received surgery (bone, brain, liver, lung metastasis and multiple organ metastases, $\mathrm{P}<0.001$; Fig. 3). Similarly, patients with only bone, brain, liver, lung metastasis and multiple metastatic lesions who received surgery on distant lesions had an improved OS compared with patients who had not received surgery (bone metastasis, $\mathrm{P}=0.043$; lung metastasis, $\mathrm{P}=0.001$; brain and multiple organ metastases, $\mathrm{P}<0.001$; Fig. 4). There was a statistically significant difference in OS between patients who had underwent surgery and those who had not received surgery. However, there was no statistically significant difference in the median OS of patients with liver metastasis who had received surgery compared with patients who had not ( $\mathrm{P}=0.388$; Fig. 4C).

Multivariate Cox proportional hazard models were used to determine the prognostic factors of patients with NSCLC with single and multiple organ metastases. The analysis in patients with single organ metastases revealed that patients with the following characteristics: i) Age ( $\leq 60)$; ii) sex (female); iii) tumor type (adenocarcinoma); iv) marital status (married); v) ethnicity (Asian); vi) $\mathrm{N}_{0}$ stage; vii) received surgery of the primary tumor (wedge resection and lobectomy) and metastatic lesion [distant tissue(s) or organ(s)]; and viii) received beam radiation therapy had improved OS and CSS compared with other patients (Table II). Using bone metastasis as a reference, patients with brain and liver metastases had a decreased OS (brain, HR, 1.162, 95\% CI, 1.106-1.220; liver, HR, 1.081, 95\% CI, 1.015-1.151), while patients with lung metastases had an improved OS (HR, 0.636; 95\% CI, 0.607-0.667). The analysis in overall metastatic patient cohort revealed that patients with the following characteristics: i) Age ( $\leq 60)$; ii) sex (female); iii) tumor type (adenocarcinoma); iv) marital status (married); v) ethnicity (Asian); vi) $\mathrm{N}_{0}$ stage; vii) one metastatic lesion; viii) received surgery of the primary (wedge resection and lobectomy) and metastatic lesion (distant tissue(s) or organ(s)); and ix) received beam radiation therapy had improved OS and CSS (Table III). Using single metastatic organ as a reference, patients with two, three and four metastases had a decreased OS (two metastases, HR, 1.336, 95\% CI, 1.294-1.379; three metastases, HR, 1.649, 95\% CI, 1.571-1.732; four metastases, HR, 1.787, 95\% CI, 1.613-1.980) and CSS (two metastases, HR, 1.322, 95\% CI, 1.275-1.372; three metastases, HR, 1.628, 95\% CI, 1.541-1.721; four metastases, HR, 1.805, 95\% CI, 1.613-2.019).

\section{Discussion}

Improvements in lung cancer diagnosis and treatment have increased the 5-year survival rate and median survival time of patients with stage IV NSCLC (15). In recent years, an increased understanding of the genetic changes involved in lung cancer has led to molecular targeted therapy (6). Additionally, surgical techniques are also rapidly evolving (16). The emergence of radiofrequency ablation (17) and endoscopy (18) has contributed to the improved safety of surgical procedures. Individualized treatment plans may reduce the occurrence of adverse events and improve the quality of life of the patients (19).

The current study involved a retrospective analysis of a large population of patients with stage IV NSCLC selected from the SEER program. Compared with patients with other organ metastases, patients with lung metastasis had the longest OS, and patients with single organ metastasis had an increased OS compared with patients with multiple organ metastases. This suggested that the type and number of metastatic organs may affect the prognosis of patients with stage IV NSCLC. 

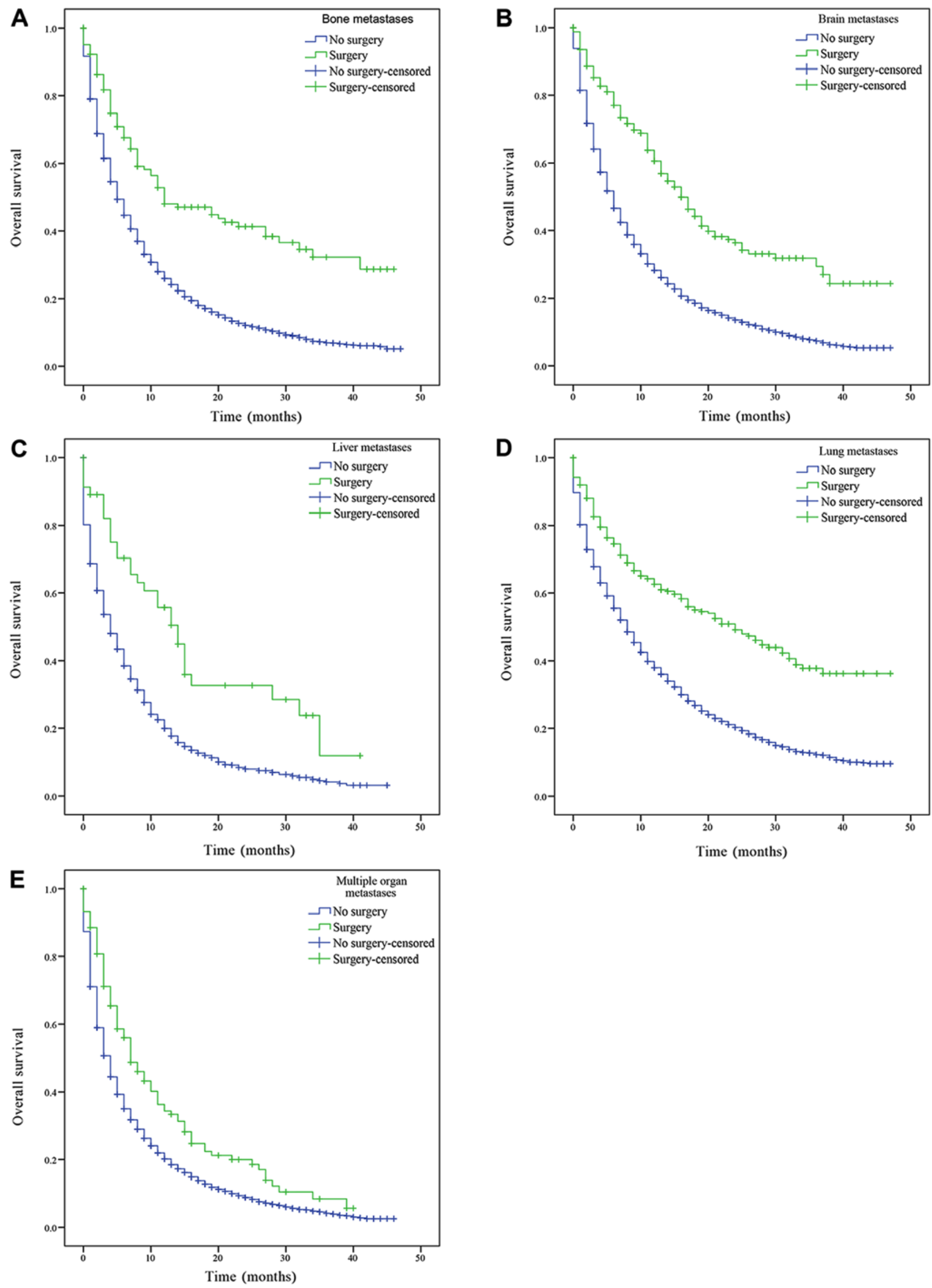

Figure 3. Kaplan-Meier curve of overall survival based on whether surgery of the primary tumor was performed. (A) Patients with isolated bone metastasis. (B) Patients with isolated brain metastasis. (C) Patients with isolated liver metastasis. (D) Patients with isolated lung metastasis. (E) Patients with multiple organ metastases. $\mathrm{P}<0.001$ surgery vs. no surgery. 

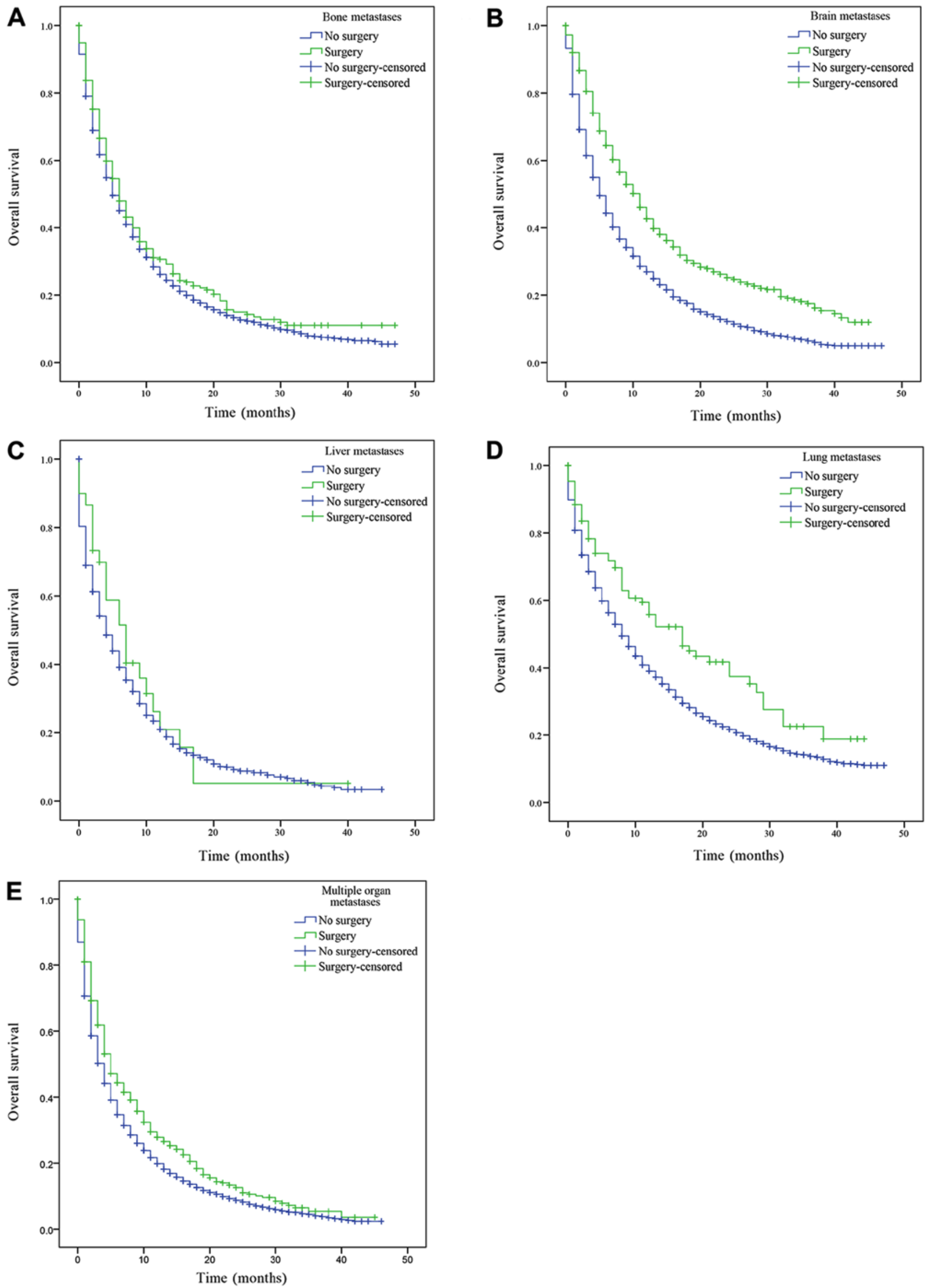

Figure 4. Kaplan-Meier curve of overall survival based on whether surgery of the metastatic lesions was performed. (A) Patients with isolated bone metastasis. $\mathrm{P}=0.043$ surgery vs. no surgery. (B) Patients with isolated brain metastasis. $\mathrm{P}<0.001$ surgery vs. no surgery. (C) Patients with isolated liver metastasis $\mathrm{P}=0.388$ surgery vs. no surgery. (D) Patients with isolated lung metastasis. $\mathrm{P}=0.001$ surgery vs. no surgery. (E) Patients with multiple organ metastases. $\mathrm{P}<0.001$ surgery vs. no surgery. 
Table II. Multivariate Cox regression analysis for OS and CSS in patients with a single metastatic site.

\begin{tabular}{|c|c|c|c|c|}
\hline \multirow[b]{2}{*}{ Variable } & \multicolumn{2}{|c|}{ OS } & \multicolumn{2}{|l|}{ CSS } \\
\hline & $\mathrm{HR}(95 \% \mathrm{CI})$ & P-value & HR $(95 \%$ CI) & P-value \\
\hline \multicolumn{5}{|l|}{ Age at diagnosis } \\
\hline$\leq 60$ & 1.00 (reference) & & 1.00 (reference) & \\
\hline$>60$ & $1.017(1.015-1.019)$ & $<0.001$ & $1.017(1.015-1.019)$ & $<0.001$ \\
\hline \multicolumn{5}{|l|}{ Sex } \\
\hline Female & 1.00 (reference) & & 1.00 (reference) & \\
\hline Male & $1.291(1.244-1.338)$ & $<0.001$ & $1.275(1.222-1.330)$ & $<0.001$ \\
\hline \multicolumn{5}{|l|}{ Tumor type } \\
\hline $\begin{array}{l}\text { Squamous cell } \\
\text { carcinomas }\end{array}$ & 1.00 (reference) & & 1.00 (reference) & \\
\hline Adenocarcinoma & $0.930(0.918-0.942)$ & $<0.001$ & $0.921(0.907-0.935)$ & $<0.001$ \\
\hline \multicolumn{5}{|l|}{ Marital status } \\
\hline Unmarried & 1.00 (reference) & & 1.00 (reference) & \\
\hline Married & $0.841(0.812-0.872)$ & $<0.001$ & $0.831(0.797-0.866)$ & $<0.001$ \\
\hline \multicolumn{5}{|l|}{ Ethnicity } \\
\hline Caucasian & 1.00 (reference) & & 1.00 (reference) & \\
\hline African-American & 1.000 (0.949-1.053) & 0.991 & $1.022(0.963-1.085)$ & 0.471 \\
\hline Asian & $0.674(0.625-0.728)$ & $<0.001$ & $0.669(0.614-0.730)$ & $<0.001$ \\
\hline Australoid & $0.717(0.457-1.125)$ & 0.148 & $0.709(0.427-1.178)$ & 0.185 \\
\hline \multicolumn{5}{|l|}{ T stage } \\
\hline 0 & 1.00 (reference) & & 1.00 (reference) & \\
\hline 1 & $0.781(0.654-0.932)$ & 0.006 & $0.845(0.689-1.035)$ & 0.104 \\
\hline 2 & $0.888(0.746-1.057)$ & 0.181 & $0.954(0.781-1.165)$ & 0.642 \\
\hline 3 & $1.008(0.847-1.200)$ & 0.931 & $1.090(0.893-1.332)$ & 0.396 \\
\hline 4 & $1.042(0.861-1.219)$ & 0.787 & $1.119(0.917-1.366)$ & 0.268 \\
\hline \multicolumn{5}{|l|}{$\mathrm{N}$ stage } \\
\hline 0 & 1.00 (reference) & & 1.00 (reference) & \\
\hline 1 & $1.134(1.059-1.214)$ & $<0.001$ & $1.114(1.029-1.207)$ & 0.008 \\
\hline 2 & $1.276(1.222-1.332)$ & $<0.001$ & $1.237(1.176-1.302)$ & $<0.001$ \\
\hline 3 & $1.340(1.271-1.413)$ & $<0.001$ & $1.314(1.235-1.398)$ & $<0.001$ \\
\hline \multicolumn{5}{|l|}{ Surgery of the primary } \\
\hline No & 1.00 (reference) & & 1.00 (reference) & \\
\hline Wedge resection & $0.718(0.630-0.819)$ & $<0.001$ & $0.687(0.586-0.805)$ & $<0.001$ \\
\hline Lobectomy & $0.361(0.305-0.428)$ & $<0.001$ & $0.346(0.281-0.426)$ & $<0.001$ \\
\hline Pneumonectomy & $0.791(0.525-1.191)$ & 0.262 & $0.840(0.535-1.319)$ & 0.449 \\
\hline \multicolumn{5}{|l|}{ Surgery of the metastases } \\
\hline No & 1.00 (reference) & & 1.00 (reference) & \\
\hline $\begin{array}{l}\text { Surgical procedure to } \\
\text { other regional sites }\end{array}$ & $0.843(0.634-1.120)$ & 0.237 & $0.786(0.572-1.082)$ & 0.140 \\
\hline $\begin{array}{l}\text { Surgical procedure to } \\
\text { distant lymph node(s) }\end{array}$ & $0.806(0.605-1.075)$ & 0.142 & $0.796(0.571-1.112)$ & 0.181 \\
\hline $\begin{array}{l}\text { Surgical procedure to } \\
\text { distant site }\end{array}$ & $0.778(0.720-0.841)$ & $<0.001$ & $0.768(0.704-0.838)$ & $<0.001$ \\
\hline $\begin{array}{l}\text { Combination of all } \\
\text { the above }\end{array}$ & $1.402(0.629-3.126)$ & 0.409 & $1.419(0.636-3.166)$ & 0.393 \\
\hline \multicolumn{5}{|l|}{ Radiation therapy } \\
\hline No & 1.00 (reference) & & 1.00 (reference) & \\
\hline Beam radiation & $0.808(0.776-0.841)$ & $<0.001$ & $0.823(0.786-0.863)$ & $<0.001$ \\
\hline Radioactive implants & $1.616(0.769-3.396)$ & 0.205 & $1.315(0.423-4.803)$ & 0.636 \\
\hline
\end{tabular}


Table II. Continued.

\begin{tabular}{|c|c|c|c|c|}
\hline \multirow[b]{2}{*}{ Variable } & \multicolumn{2}{|c|}{ OS } & \multicolumn{2}{|l|}{ CSS } \\
\hline & $\mathrm{HR}(95 \% \mathrm{CI})$ & P-value & HR $(95 \%$ CI $)$ & P-value \\
\hline Radioisotopes & $1.317(0.494-3.512)$ & 0.582 & $1.264(0.407-3.923)$ & 0.685 \\
\hline $\begin{array}{l}\text { Combination of } 2 \text { or } \\
3 \text { above }\end{array}$ & $0.958(0.430-2.135)$ & 0.916 & $0.987(0.410-2.377)$ & 0.976 \\
\hline \multicolumn{5}{|l|}{ Metastatic site } \\
\hline Bone only & 1.00 (reference) & & 1.00 (reference) & \\
\hline Brain only & $1.162(1.106-1.220)$ & $<0.001$ & $1.131(1.070-1.197)$ & $<0.001$ \\
\hline Liver only & $1.081(1.015-1.151)$ & 0.016 & $1.075(0.999-1.157)$ & 0.053 \\
\hline Lung only & $0.636(0.607-0.667)$ & $<0.001$ & $0.635(0.600-0.671)$ & $<0.001$ \\
\hline
\end{tabular}

OS, overall survival; CSS, cancer-specific survival; HR, hazard ratio; CI, confidence interval.

This is similar to previously published studies investigating bladder and colorectal cancer (20,21). Furthermore, the current study established that surgical resection of the primary and metastatic organs may significantly improve the prognosis of patients with stage IV NSCLC.

The current study demonstrated that patients with only lung metastases had the best prognosis, patients with only brain metastases had a slightly improved prognosis compared with patients with only bone metastases, while those with liver metastases had the worst prognosis. Patients with only one metastasis had an improved prognosis compared with patients with multiple metastases. Previous studies have revealed similar results; patients with NSCLC and SCLC with liver metastasis and multiple metastases have the worst prognosis (22-25). Similar results were obtained using the AJCC staging system, where the number of metastatic organs had an effect on the prognosis of patients (26). Notably, the effect of the number of metastases is not same for different types of cancer, the OS of patients with pancreatic cancer is not affected by either single or multiple organ metastases (27). Pancreatic cancer is characterized by rapid growth, abundant pancreatic blood and lymphatic vessels, and incomplete pancreatic capsule. Therefore, the time of distant metastasis is relatively early, so whether there is distant metastasis or not, has little impact on OS (28).

Multivariate Cox regression analysis revealed that the prognosis of patients who underwent surgery for primary and metastatic lesions was better compared with patients who did not undergo the above. Surgical treatment remains the main approach used for the treatment of the majority of malignant tumors (16). Previously published studies revealed that certain patients with advanced NSCLC with unilateral contralateral lung metastasis, single brain, bone or adrenal metastasis may be treated surgically (29-31). For patients with NSCLC with isolated metastases and resectable pulmonary lesions, resection of the metastatic organs may also be considered. However, how isolated liver metastases should be removed remains unclear (32-34). Previous studies demonstrated that surgery serves an important role in the treatment of liver metastasis of neuroendocrine carcinoma and colorectal cancer, but not in lung cancer $(32,35)$. With advances in liver resection and the continuous improvement of surgical safety, previous case reports described surgical resection of liver metastatic carcinoma with satisfactory results $(33,34)$.

The benefit of surgical treatment on the prognosis of patients with advanced lung cancer remains controversial (29-32). A previous study based on SEER program analysis suggested that no further surgical treatment is recommended for patients with advanced lung cancer (36). However, additional studies do not concur with this recommendation (37). Patients with stage IV NSCLC who received pneumonectomy and thoracic wall enlargement resection had an improved quality of life and 5-year survival (38). However, this is contrary to what was observed in the current study. Results from a previous study suggested that the long-term survival rate of patients is related to the degree of tumor infiltration into the chest wall, and thus the scope of resection should be determined according to the degree of infiltration (39). Using the SEER program, previous studies have revealed that the size of the lung cancer lesions should guide the choice of surgical intervention and expanding the scope of surgical resection will not improve prognosis (40). A previous study revealed that lymph node dissection for distant metastatic lesions is necessary to improve the prognosis (41). Taken together, the results from the aforementioned studies suggest that it is important to identify specific patients who may benefit from surgical procedures.

Radiotherapy is widely used for patients with advanced lung cancer (42). A previous study revealed that surgery following radiotherapy may be beneficial to patients (43). The most commonly employed method of radiotherapy is beam radiation (44), which was consistent with the results obtained in the current study. However, previous studies reported that radioactive implants and radioisotopes may offer promising results for patients with advanced NSCLC $(45,46)$.

Multivariate Cox regression analysis revealed that age, sex, marital status, ethnicity, $\mathrm{N}$ stage and tumor type affected the prognosis of patients with NSCLC in the current study. Patients $>60$ years had an improved prognosis compared with other patients. Toffart et al (47) revealed that patients with NSCLC $>63$ years had significantly decreased OS compared with other 
Table III. Multivariate Cox regression analysis for OS and CSS in overall metastatic patient cohort.

\begin{tabular}{|c|c|c|c|c|}
\hline \multirow[b]{2}{*}{ Variable } & \multicolumn{2}{|l|}{ OS } & \multicolumn{2}{|l|}{ CSS } \\
\hline & $\mathrm{HR}(95 \% \mathrm{CI})$ & P-value & $\mathrm{HR}(95 \% \mathrm{CI})$ & P-value \\
\hline \multicolumn{5}{|l|}{ Age at diagnosis } \\
\hline$\leq 60$ & 1.00 (reference) & & 1.00 (reference) & \\
\hline$>60$ & $1.269(1.229-1.310)$ & $<0.001$ & $1.275(1.231-1.321)$ & $<0.001$ \\
\hline \multicolumn{5}{|l|}{ Sex } \\
\hline Female & 1.00 (reference) & & 1.00 (reference) & \\
\hline Male & $1.287(1.251-1.324)$ & $<0.001$ & $1.281(1.240-1.323)$ & $<0.001$ \\
\hline \multicolumn{5}{|l|}{ Tumor types } \\
\hline Squamous cell carcinomas & 1.00 (reference) & & 1.00 (reference) & \\
\hline Adenocarcinoma & $0.930(0.920-0.940)$ & $<0.001$ & $0.920(0.909-0.931)$ & $<0.001$ \\
\hline \multicolumn{5}{|l|}{ Marital status } \\
\hline Unmarried & 1.00 (reference) & & 1.00 (reference) & \\
\hline Married & $0.834(0.811-0.857)$ & $<0.001$ & $0.823(0.797-0.849)$ & $<0.001$ \\
\hline \multicolumn{5}{|l|}{ Ethnicity } \\
\hline Caucasian & 1.00 (reference) & & 1.00 (reference) & \\
\hline African-American & $0.964(0.825-1.004)$ & 0.074 & $0.981(0.937-1.028)$ & 0.421 \\
\hline Asian & $0.658(0.622-0.696)$ & $<0.001$ & $0.655(0.616-0.697)$ & $<0.001$ \\
\hline Australoid & $0.745(0.544-1.021)$ & 0.067 & $0.721(0.507-1.026)$ & 0.069 \\
\hline \multicolumn{5}{|l|}{ T stage } \\
\hline 0 & 1.00 (reference) & & 1.00 (reference) & \\
\hline 1 & $0.756(0.649-0.882)$ & $<0.001$ & $0.831(0.697-0.990)$ & 0.039 \\
\hline 2 & $0.850(0.732-0.988)$ & 0.034 & $0.928(0.781-1.102)$ & 0.393 \\
\hline 3 & $0.874(0.753-1.016)$ & 0.079 & $0.964(0.812-1.145)$ & 0.675 \\
\hline 4 & $0.842(0.725-0.978)$ & 0.024 & $0.933(0.787-1.107)$ & 0.430 \\
\hline \multicolumn{5}{|l|}{$\mathrm{N}$ stage } \\
\hline 0 & 1.00 (reference) & & 1.00 (reference) & \\
\hline 1 & $1.129(1.069-1.193)$ & $<0.001$ & $1.122(1.052-1.196)$ & $<0.001$ \\
\hline 2 & $1.231(1.188-1.274)$ & $<0.001$ & $1.190(1.143-1.240)$ & $<0.001$ \\
\hline 3 & $1.194(1.145-1.245)$ & $<0.001$ & $1.175(1.120-1.234)$ & $<0.001$ \\
\hline \multicolumn{5}{|l|}{ Surgery of the primary } \\
\hline No & 1.00 (reference) & & 1.00 (reference) & \\
\hline Wedge resection & $0.670(0.598-0.750)$ & $<0.001$ & $0.670(0.587-0.765)$ & $<0.001$ \\
\hline Lobectomy & $0.362(0.308-0.424)$ & $<0.001$ & $0.349(0.287-0.425)$ & $<0.001$ \\
\hline Pneumonectomy & $0.720(0.486-1.066)$ & 0.101 & $0.774(0.504-1.188)$ & 0.242 \\
\hline \multicolumn{5}{|l|}{ Surgery of the metastases } \\
\hline No & 1.00 (reference) & & 1.00 (reference) & \\
\hline Surgical procedure to other regional sites & $0.857(0.676-1.086)$ & 0.202 & $0.836(0.638-1.096)$ & 0.194 \\
\hline Surgical procedure to distant lymph node(s) & $0.883(0.713-1.093)$ & 0.252 & $0.875(0.686-1.118)$ & 0.286 \\
\hline Surgical procedure to distant site & $0.852(0.802-0.906)$ & $<0.001$ & $0.829(0.775-0.888)$ & $<0.001$ \\
\hline Combination of all the above & $1.021(0.604-1.726)$ & 0.938 & $0.984(0.570-1.697)$ & 0.952 \\
\hline \multicolumn{5}{|l|}{ Radiation therapy } \\
\hline No & 1.00 (reference) & & 1.00 (reference) & \\
\hline Beam radiation & $0.881(0.856-0.906)$ & $<0.001$ & $0.892(0.864-0.921)$ & $<0.001$ \\
\hline Radioactive implants & $1.498(0.805-2.786)$ & 0.202 & $1.302(0.585-2.901)$ & 0.518 \\
\hline Radioisotopes & $0.646(0.308-1.335)$ & 0.248 & $0.613(0.255-1.475)$ & 0.275 \\
\hline Combination of 2 or 3 above & $0.821(0.454-1.484)$ & 0.513 & $1.051(0.565-1.958)$ & 0.874 \\
\hline \multicolumn{5}{|l|}{ Number of metastatic sites } \\
\hline Single & 1.00 (reference) & & 1.00 (reference) & \\
\hline Double & $1.336(1.294-1.379)$ & $<0.001$ & $1.322(1.275-1.372)$ & $<0.001$ \\
\hline
\end{tabular}


Table III. Continued.

\begin{tabular}{lccccc}
\hline & \multicolumn{2}{c}{ OS } & & \multicolumn{2}{c}{ CSS } \\
\cline { 2 - 3 } Variable & HR $(95 \% \mathrm{CI})$ & P-value & & HR $(95 \% \mathrm{CI})$ & P-value \\
\hline Triple & $1.649(1.571-1.732)$ & $<0.001$ & & $1.628(1.541-1.721)$ & $<0.001$ \\
Four & $1.787(1.613-1.980)$ & $<0.001$ & & $1.805(1.613-2.019)$ & $<0.001$ \\
\hline
\end{tabular}

OS, overall survival; CSS, cancer-specific survival; HR, hazard ratio; CI, confidence interval.

younger patients using a multivariate cox analysis $(\mathrm{HR}=1.63$; 95\% CI: 1.013-2.63; $\mathrm{P}=0.04)$. The current study demonstrated that the prognosis of female patients was improved compared with male patient. This may be attributed to different hormone and corresponding receptor expression levels (48). In terms of marital status, previous large epidemiological studies revealed that marriage benefits patients with less aggressive cancer $(49,50)$, which is consistent with the results obtained in the current study. The effect of ethnicity on the prognosis of patients with NSCLC patients remains controversial (51-54). A previous study revealed that African-Americans with lung cancer had a decreased 5-year survival rate compared with Caucasians (51). Similar survival rates for African-Americans and Caucasians have been reported for patients with lung cancer $(52,53)$. Tannenbaum et al (54) reported that Asian patients with NSCLC had significantly increased survival rates compared with Caucasian patients, which is consistent with the results obtained in the current study.

The results obtained in the current study suggested that there was no statistical difference in the prognosis of patients with different $\mathrm{T}$ stages. This is not in accordance with the AJCC staging system. However, the patients selected in the current study all had stage IV NSCLC, according to the 7 Edition of the AJCC staging system with only four sites of metastases identified, and may not conform with the principles of the staging system, due to a limited representative sample. The current study revealed that the $\mathrm{N}$ stage influenced the prognosis of patients with stage IV NSCLC. This was consistent with a previous study which suggested that lymph node metastasis is an adverse prognostic factor for the surgical treatment of patients with advanced NSCLC (55). The aforementioned study recommended that patients with $\mathrm{N}_{0}$ stage should be eligible for surgical treatment and that surgery for patients with extensive lymph node metastases may not be beneficial (55). There are few studies investigating the prognosis of patients with stage IV NSCLC with adenocarcinoma and squamous carcinoma $(56,57)$. A retrospective study of 148 Chinese patients with NSCLC revealed that non-lung adenocarcinoma was a prognostic risk factor in patients with NSCLC (57), consistent with the results obtained in the current study.

The present study had certain limitations. Firstly, due to the retrospective nature of the study, confounding factors, such as smoking history and age, were not easily excluded. Secondly, the specific chemotherapy regimens and radiation doses were not detailed in the SEER program, and these may have had an impact on the prognosis of the patients (58).
Thirdly, the SEER program did not include data on whether the patients were treated with tyrosine kinase inhibitors, due to EGFR mutations being more prevalent in non-smoking, female, Asian patients (59). The OS would be affected if they were treated with tyrosine kinase inhibitors (6), influencing our conclusions. Finally, more distal metastases, such as in the adrenal gland and gastrointestinal tract, cannot be included without relevant data, and at the same time, the sequence of metastatic lesions cannot be determined. The results obtained in the current study require further examination by future well-designed studies to validate this study's results.

\section{Acknowledgements}

Not applicable.

\section{Funding}

No funding was received.

\section{Availability of data and materials}

The datasets generated and/or analyzed during the current study are available in the Surveillance, Epidemiology, and End Results (SEER) repository (https://seer.cancer.gov/).

\section{Authors' contributions}

YL designed the study, work that led to the submission, acquired data and played an important role in interpreting the results. XF and XW analyzed the data and revised the manuscript. All authors read and approved the final manuscript.

\section{Ethics approval and consent to participate}

The SEER database does not include any human or demographic identifying information, and the data used for analysis were de-identified. Therefore, ethics approval and formal informed consent to participate was not required.

\section{Patient consent for publication}

Not applicable.

\section{Competing interests}

The authors declare that they have no competing interests. 


\section{References}

1. Bray F, Ferlay J, Soerjomataram I, Siegel RL, Torre LA and Jemal A: Global cancer statistics 2018: GLOBOCAN estimates of incidence and mortality worldwide for 36 cancers in 185 countries. CA Cancer J Clin 68: 394-424, 2018.

2. Siegel RL, Miller KD and Jemal A: Cancer statistics, 2018. CA Cancer J Clin 68: 7-30, 2018

3. Noone AM, Howlader N, Krapcho M, Miller D, Brest A, $\mathrm{Yu}$ M, Ruhl J, Tatalovich Z, Mariotto A, Lewis DR, et al: SEER Cancer Statistics Review, 1975-2015, National Cancer Institute. Bethesda, MD, 2018. https://seer.cancer.gov/archive/ csr/1975_2015/. Accessed September 10, 2018

4. Duan L, Pang HL, Chen WJ, Shen WW, Cao PP, Wang SM, Liu LL and Zhang HL: The role of GDF15 in bone metastasis of lung adenocarcinoma cells. Oncol Rep 41: 2379-2388, 2019.

5. Riihimäki M, Hemminki A, Fallah M, Thomsen H, Sundquist K, Sundquist $\mathbf{J}$ and Hemminki K: Metastatic sites and survival in lung cancer. Lung Cancer 86: 78-84, 2014.

6. Wang Y, Xie S and He B: Effect of EGFR gene polymorphism on efficacy of chemotherapy combined with targeted therapy for non-small cell lung cancer in Chinese patients. Am J Cancer Res 9: 619-627, 2019.

7. Sosa Iglesias V, Giuranno L, Dubois LJ, Theys $\mathbf{J}$ and Vooijs $\mathrm{M}$ : Drug resistance in non-small cell lung cancer: A potential for NOTCH Targeting? Front Oncol 8: 267, 2018.

8. Kogure Y: Cost effectiveness and health economics of immune checkpoint inhibitors for non-small cell lung cancer. Gan To Kagaku Ryoho 45: 781-784, 2018 (In Japanese).

9. Skinner KE, Fernandes AW, Walker MS Pavilack M and VanderWalde A: Healthcare costs in patients with advanced non-small cell lung cancer and disease progression during targeted therapy: A real-world observational study. J Med Econ 21: 192-200, 2018

10. Furák J, Troján I, Szöke T, Agócs L, Csekeö A, Kas J, Svastics E, Eller $\mathrm{J}$ and Tiszlavicz L: Lung cancer and its operable brain metastasis: Survival rate and staging problems. Ann Thorac Surg 79: 241-247, 2005

11. Hanagiri T, Takenaka M, Oka S, Shigematsu Y, Nagata Y, Shimokawa H, Uramoto H and Tanaka F: Results of a surgical resection for patients with stage IV non-small-cell lung cancer. Clin Lung Cancer 13: 220-224, 2012.

12. Congedo MT, Cesario A, Lococo F, De Waure C, Apolone G, Meacci E, Cavuto S and Granone P: Surgery for oligometastatic non-small cell lung cancer: Long-term results from a single center experience. J Thorac Cardiovasc Surg 144: 444-452, 2012.

13. Tieqin L, Hongxu L, Yu L, Shun X and Chunlu Y: Influencing factors of survival rate on 44 cases of postoperative stage IV non-small-celllung cancer. Chin J Ciinicians (Eiectronic Ed) 7: 605-608, 2013

14. Edge SB, Byrd DR, Compton CC, Fritz AG, Greene FL and Trotti A (eds.): AJCC Cancer Staging Manual. 7th edition. Springer, New York, NY, 2009.

15. Delea $T$, Langer $C$, McKiernan J, Liss M, Edelsberg J, Brandman J, Sung J, Raut M and Oster G: The cost of treatment of skeletal-related events in patients with bone metastases from lung cancer. Oncology 67: 390-396, 2004

16. Hofferberth SC, Grinstaff MW and Colson YL: Nanotechnology applications in thoracic surgery. Eur J Cardiothorac Surg 50: 6-16, 2016.

17. Vaughn C, Mychaskiw G II and Sewell P: Massive hemorrhage during radiofrequency ablation of a pulmonary neoplasm. Anesth Analg 94: 1149-1151, 2002.

18. Tutar N, Yurci A, Güneş I, Gülmez İ, Gürsoy Ş, Önal Ö and Canöz Ö: The role of endobronchial and endoscopic ultrasound guided fine needle aspiration for mediastinal nodal staging of non-small-cell lung cancer. Tuberk Toraks 66: 85-92, 2018.

19. Reck M and Rabe KF: Precision diagnosis and treatment for advanced non-small-cell lung cancer. N Engl J Med 377: 849-861, 2017.

20. Dong F, Shen Y, Gao F, Xu T, Wang X, Zhang X, Zhong S, Zhang M, Chen S and Shen Z: Prognostic value of site-specific metastases and therapeutic roles of surgery for patients with metastatic bladder cancer: A population-based study. Cancer Manag Res 9: 611-626, 2017.

21. Luo D, Liu Q, Yu W, Ma Y, Zhu J, Lian P, Cai S, Li Q and Li X: Prognostic value of distant metastasis sites and surgery in stage IV colorectal cancer: A population-based study. Int J Colorectal Dis 33: 1241-1249, 2018.
22. Tamura T, Kurishima K, Nakazawa K, Kagohashi K, Ishikawa H, Satoh $\mathrm{H}$ and Hizawa N: Specific organ metastases and survival in metastatic non-small-cell lung cancer. Mol Clin Oncol 3: 217-221, 2015.

23. Nakazawa K, Kurishima K, Tamura T, Kagohashi K, Ishikawa H, Satoh $\mathrm{H}$ and Hizawa N: Specific organ metastases and survival in small cell lung cancer. Oncol Lett 4: 617-620, 2012.

24. Yang J, Zhang Y, Sun X, Gusdon AM, Song N, Chen L, Jiang G and Huang Y: The prognostic value of multiorgan metastases in patients with non-small cell lung cancer and its variants: A SEER-based study. J Cancer Res Clin Oncol 144: 1835-1842, 2018.

25. Gibson AJW, Li H, D'Silva A, Tudor RA, Elegbede AA, Otsuka SM, Bebb DG and Cheung WY: Impact of number versus location of metastases on survival in stage IV M1b non-small cell lung cancer. Med Oncol 35: 117, 2018.

26. Rami-Porta R, Bolejack V, Crowley J, Ball D, Kim J, Lyons G, Rice T, Suzuki K, Thomas CF Jr, Travis WD, et al: The IASLC lung cancer staging project: Proposals for the revisions of the $\mathrm{T}$ descriptors in the forthcoming eighth edition of the TNM classification for lung cancer. J Thorac Oncol 10: 990-1003, 2015.

27. Oweira H, Petrausch U, Helbling D, Schmidt J, Mannhart M, Mehrabi A, Schöb O, Giryes A, Decker M and Abdel-Rahman O: Prognostic value of site-specific metastases in pancreatic adenocarcinoma: A Surveillance Epidemiology and End Results database analysis. World J Gastroenterol 23: 1872-1880, 2017.

28. Hidalgo M: Pancreatic cancer. N Engl J Med 362: 1605-1617, 2010.

29. Shi Y, Sun Y, Yu J, Ding C, Wang Z, Wang C, Wang D, Wang C, Wang Z, Wang M, et al: China experts consensus on the diagnosis and treatment of advanced stage primary lung cancer (2016 version). Asia Pac J Clin Oncol 13: 87-103, 2017.

30. Shi Y, Sun Y, Yu J, Ding C, Ma Z, Wang Z, Wang D, Wang Z, Wang M, Wang Y, et al: China experts consensus on the diagnosis and treatment of brain metastases of lung cancer (2017 version). Zhongguo Fei Ai Za Zhi 20: 1-13, 2017 (In Chinese).

31. Sun Y, Guan Z, Liao M, Yu X, Wang C, Wang J, Niu X, Shi Y, Zhi X, Liu Y, et al: Expert consensus on the diagnosis and treatment of bone metastasis in lung cancer (2014 version). Zhongguo Fei Ai Za Zhi 17: 57-72, 2014 (In Chinese).

32. Schmelzle M, Eisenberger CF, Am Esch JS II, Matthaei H, Krausch M and Knoefel WT: Non-colorectal, non-neuroendocrine, and non-sarcoma metastases of the liver: Resection as a promising tool in the palliative management. Langenbecks Arch Surg 395: 227-234, 2010.

33. Ileana E, Greillier L, Moutardier V and Barlesi F: Surgical resection of liver non-small cell lung cancer metastasis: A dual weapon? Lung Cancer 70: 221-222, 2010.

34. Di Carlo I, Grasso G, Patane' D, Russello D and Latteri F: Liver metastases from lung cancer: Is surgical resection justified? Ann Thorac Surg76: 291-293, 2003.

35. Reddy SK, Barbas AS, Marroquin CE, Morse MA, Kuo PC and Clary BM: Resection of noncolorectal nonneuroendocrine liver metastases: A comparative analysis. J Am Coll Surg 204: 372-382, 2007.

36. Abdel-Rahman O: Outcomes of surgery as part of the management of metastatic Non-small-cell lung cancer: A Surveillance, epidemiology and End results database analysis. Cancer Invest 36: 238-245, 2018.

37. Liu K, Zheng D, Xu G, Du Z and Wu S: Local thoracic therapy improve prognosis for stage IV non-small cell lung cancer patients combined with chemotherapy: A Surveillance, Epidemiology, and End results database analysis. PLoS One 12: e0187350, 2017.

38. Setzer M, Robinson LA and Vrionis FD: Management of locally advanced pancoast (superior sulcus) tumors with spine involvement. Cancer Control 21: 158-167, 2014.

39. Rui M, Pengqing $Y$ and Chang C: Progress in resection and reconstruction of chest wall in non-small lung cancer. Chin J Clin Thorac Cardiovasc Surg 22: 685-690, 2015.

40. Dai C, Shen J, Ren Y, Zhong S, Zheng H, He J, Xie D, Fei K, Liang W, Jiang G, et al: Choice of surgical procedure for patients with Non-small-cell lung cancer $\leq 1 \mathrm{~cm}$ or $>1$ to $2 \mathrm{~cm}$ among lobectomy, segmentectomy, and wedge resection: A population-based study. J Clin Oncol 34: 3175-3182, 2016.

41. Ludwig MS, Goodman M, Miller DL and Johnstone PA: Postoperative survival and the number of lymph nodes sampled during resection of node-negative non-small cell lung cancer. Chest 128: 1545-1550, 2005. 
42. Zhang R, Li P, Li Q, Qiao Y, Xu T, Ruan P, Song Q and Fu Z: Radiotherapy improves the survival of patients with stage IV NSCLC: A propensity score matched analysis of the SEER database. Cancer Med 7: 5015-5026, 2018.

43. Herskovic A, Chitti B, Christos P, Wernicke AG and Parashar B: Addition of surgery after radiation significantly improves survival in stage IIIB Non-small cell lung cancer: A population-based analysis. World J Surg 41: 758-762, 2017.

44. Verma V, Rwigema JM, Adeberg S and Simone CB II: Enrollment of elderly patients with locally advanced non-small cell lung cancer in multi-institutional trials of proton beam radiation therapy. Clin Lung Cancer 18: 441-443, 2017.

45. He M,Li S, Chen Y, Ouyang M, Chen P and Zhang J: 131I-chTNT injection to relieve tracheal obstruction in advanced NSCLC patient. Technol Health Care 24 (Suppl 2): S513-S519, 2016.

46. Hendriks LE, Hermans BC, van den Beuken-van Everd ingen $\mathrm{MH}$, Hochstenbag MM and Dingemans AM: Effect of Bisphosphonates, Denosumab, and radioisotopes on bone pain and quality of life in patients with non-small cell lung cancer and bone metastases: A systematic review. J Thorac Oncol 11 $155-173,2016$.

47. Toffart AC, Duruisseaux M, Brichon PY, Pirvu A, Villa J, Selek L, Guillem P, Dumas I, Ferrer L, Levra MG and Moro-Sibilot D: Operation and chemotherapy: Prognostic factors for lung cancer with one synchronous metastasis. Ann Thorac Surg 105: 957-965, 2018.

48. Cheng TD, Darke AK, Redman MW, Zirpoli GR, Davis W, Payne Ondracek R, Bshara W, Omilian AR, Kratzke R, Reid ME, et al: Smoking, Sex, and Non-small cell lung cancer: Steroid hormone receptors in tumor tissue (S0424). J Natl Cancer Inst 110: 734-742, 2018.

49. Merrill RM and Johnson E: Benefits of marriage on relative and conditional relative cancer survival differ between males and females in the USA. J Cancer Surviv 11: 578-589, 2017.

50. Wu Y, AiZ and Xu G: Marital status and survival in patients with non-small cell lung cancer: An analysis of 70006 patients in the SEER database. Oncotarget 8: 103518-103534, 2017.

51. Richards TB, Henley SJ, Puckett MC, Weir HK, Huang B, Tucker TC and Allemani C: Lung cancer survival in the United States by race and stage (2001-2009): Findings from the CONCORD-2 study. Cancer 123: 5079-5099, 2017.
52. Williams CD, Salama JK, Moghanaki D, Karas TZ and Kelley MJ: Impact of race on treatment and survival among U.S. Veterans with early-stage lung cancer. J Thorac Oncol 11: 1672-1681, 2016.

53. Videtic GM, Reddy CA, Chao ST, Rice TW, Adelstein DJ, Barnett GH, Mekhail TM, Vogelbaum MA and Suh JH: Gender, race, and survival: A study in non-small-cell lung cancer brain metastases patients utilizing the radiation therapy oncology group recursive partitioning analysis classification. Int $\mathbf{J}$ Radiat Oncol Biol Phys 75: 1141-1147, 2009.

54. Tannenbaum SL, Koru-Sengul T, Zhao W, Miao F and Byrne MM: Survival disparities in non-small cell lung cancer by race, ethnicity, and socioeconomic status. Cancer J 20: 237-245, 2014.

55. Yoshinaga Y, Enatsu S, Iwasaki A and Shirakusa T: Surgical treatment for primary non-small cell lung cancer with synchronous brain metastases. Kyobu Geka 59: 41-45, 2016 (In Japanese).

56. Ramalingam S, Dinan MA and Crawford J: Survival comparison in patients with Stage IV lung cancer in Academic versus Community centers in the United States. J Thorac Oncol 13: 1842-1850, 2018

57. Xiaolan J and Jia W: Prognostic factors for bone metastasis of patients with non-small-cell lung cancer. Shandong Med 56: 88-90, 2016.

58. Masters GA, Temin S, Azzoli CG, Giaccone G, Baker S Jr, Brahmer JR, Ellis PM, Gajra A, Rackear N, Schiller JH, et al: Systemic therapy for stage IV non-small-cell lung cancer: American Society of Clinical Oncology Clinical Practice Guideline Update. J Clin Oncol 33: 3488-3515, 2015.

59. Zhang YL, Yuan JQ, Wang KF, Fu XH, Han XR, Threapleton D, Yang ZY, Mao C and Tang JL: The prevalence of EGFR mutation in patients with non-small cell lung cancer: A systematic review and meta-analysis. Oncotarget 7: 78985-78993, 2016.

This work is licensed under a Creative Commons Attribution-NonCommercial-NoDerivatives 4.0 International (CC BY-NC-ND 4.0) License. 